\title{
A CIDADE IDEAL: O PATRIMÔNIO CULTURAL NOS PLANOS DIRETORES DOS MUNICÍPIOS DE CRATO E JUAZEIRO DO NORTE - CEARÁ
}

\author{
THE IDEAL CITY: THE CULTURAL HERITAGE IN THE DIRECTORS 'PLANS \\ OF THE MUNICIPALITIES OF CRATO AND JUAZEIRO DO NORTE - CEARÁ \\ Polliana de Luna Nunes Barreto ${ }^{1}$ \\ Barbara Almeida Oliveira ${ }^{2}$
}

1

Doutora em Educação pela Universidade Federal do Ceará (UFC). Docente da Universidade Federal do Cariri (UFCA). ORCID: 0000-0003-3936-6002. Correio eletrônico: polliana. luna@ufca.edu.br 2

Historiadora pela Universidade Regional do Cariri (URCA). Graduanda em Administração Pública pela Universidade Federal do Cariri (UFCA). ORCID: oooo-0oo1-96506345. Correio eletrônico: barbaraalmeidaoliveira@ gmail.com
Resumo: A Política Urbana, delineada na Constituição Federal de 1988, orienta-se pela perspectiva do pleno desenvolvimento das funções sociais da cidade apresenta entre suas diretrizes a proteção, preservação e recuperação, tanto do meio ambiente natural e construído, como do patrimônio cultural, histórico, artístico, paisagístico e arqueológico. Diante do exposto, através de uma abordagem qualitativa, apoiada no método da pesquisa documental, buscamos compreender as relações entre o planejamento urbano e o patrimônio cultural. Para tanto, utilizamos como fontes o Plano Diretor de Desenvolvimento Urbano (PDDU) de dois municípios da Região Metropolitana do Cariri cearense. A escolha desses territórios se sustenta pela proximidade de seus territórios, compreendida tanto pela circulação de capital humano como econômico, pela sua vinculação sócio-histórica, e pela inserção na política de descentralização do planejamento urbano empreendida pelo governo estadual na década de 1990. Observamos como principal achado a desatualização dos Planos Diretores, uma vez que a legislação prevê a revisão desses instrumentos, pelo menos, em um prazo de dez anos, e os ambos encontram-se sem revisão já a mais de uma década.

palavras-Chave: Patrimônio Cultural. Planejamento Urbano. Gestão Pública.

ABStract: The Urban Policy, based on the full development of the city's social functions, has as one of its guidelines the "protection, preservation and recovery of the natural and built environment, cultural, historical, artistic, landscape and archaeological heritage" (BRASIL, 1988), determinant dimension in the organization of the city. Given the above, through a qualitative approach, supported by the documentary research method, we seek to understand the relationships between urban planning and cultural heritage. To do so, we used the Urban Development Master Plan (PDDU) of two municipalities in the Cariri Metropolitan Region of Ceará as sources. The choice of these territories is supported by the proximity of their territories, understood both by the circulation of human and economic capital, by their socio-historical link, and by the insertion in the policy of decentralization of urban planning undertaken by the state government in the 1990s. main finding is the outdating of the Master Plans, since the legislation provides for the revision of these instruments, at least, in a period of ten years, and both have been without revision for more than a decade.

KEywords: Cultural Heritage. Urban Planning. Public Management. 


\section{INTRODUÇÃO}

Em 1976 Chico Buarque adaptava a canção "A Cidade Ideal", para o musical infantil dos Saltimbancos. A cidade ideal cantarolada pelas personagens nos permite refletir sobre as concepções que temos destes espaços. Nesse sentido, os instrumentos normativos são um bom exemplo de como se define e organizar essa cidade. Partindo da concepção de uma "cidade ideal" ou a cidade pensada para a coletividade, a Constituição Federal de 1988, em seus artigos 182 e 183, prevê elementos que devem ser tomados no processo de construção desses territórios, orientados tanto pela perspectiva do pleno desenvolvimento das funções sociais da cidade, como pela garantia do bem-estar de seus habitantes (BRASIL, 1988). Definições coroadas como a promulgação do Estatuto da Cidade (Lei no 10.257/2001) que regulamenta e delineia as diretrizes gerais da política urbana. A Política Urbana, regulamentada pela Lei $\mathrm{n}^{\mathrm{o}}$ 10.257/2001, reafirma a competência dos municípios em legislar sobre a política de desenvolvimento e expansão urbana, utilizando como instrumento básico o Plano Diretor.

A Política Urbana pensada pela perspectiva do pleno desenvolvimento das funções sociais da cidade e da propriedade urbana (BRASIL, 2001, Art. $2^{\circ}$ ) traz como uma de suas diretrizes gerais no inciso XII a previsão da "proteção, preservação e recuperação do meio ambiente natural e construído, do patrimônio cultural, histórico, artístico, paisagístico e arqueológico", dimensão esta compreendida como um dos fatores determinante na organização do espaço da cidade.

A relação entre Patrimônio Cultural e a promoção de espaços de vivência e experiência são amplamente divulgados na literatura e aqui destacamos alguns estudiosos de relevo como Choay (2011); Funari, Pelegrini (2006); Lencione (2008), Casco e Amorim (2001); Rolnik et al (2014); Castriota, (2013); Starling, (2012) e Canclini (2013), sem prejuízo das demais contribuições que nortearam a elaboração temática deste manuscrito, bem como a análise dos dados. Contudo, à luz do referencial produzido pelos estudos anteriores, consideramos uma lacuna a ser observada, a carência de trabalhos que focalizem a região do Cariri cearense no âmbito das pesquisas que tratem do patrimônio cultural como ferramenta da gestão pública e objeto de suas políticas. Nesse sentido, esta comunicação vem apresentar uma contribuição a respeito.

Diante disso, o objetivo deste estudo é analisar a inserção do Patrimônio Cultural - tanto nas suas dimensões material, como imaterial - no processo de planejamento urbano nas cidades de Juazeiro do Norte e Crato. O recorte territorial engloba as comunidades juazeirense e cratense, ambas estão historicamente relacionadas. Têm em seus aspectos culturais, sociais e políticos consonâncias e dissonâncias.

A base das fontes documentais é os Planos Diretores das duas cidades. A exploração dos instrumentos normativos possibilitou compreender como se estrutura a gestão do Patrimônio Cultural, tanto em

I "A Cidade Ideal” composta pelos italianos Sérgio Bardotti e Luis Enriquez Bacalov foi adaptada por Chico Buarque em 1976 para o musical infantil dos Saltimbancos. 
suas dimensões material como imaterial, na dinâmica do planejamento urbano, em contextos específicos e distintos, mas que se relacionam entre si não apenas pela proximidade de seus territórios, compreendida tanto pela circulação de capital humano como também econômico.

Para tanto, utilizar-se-á como metodologia de pesquisa a abordagem qualitativa, uma vez que essa lida com "o universo dos significados, dos motivos e aspirações, das crenças, dos valores e das atividades" (MINAYO et al. 2011, p. 21). Quanto aos procedimentos técnicos para coleta e tratamento das informações e dados, adotar-se-á o método da pesquisa documental (GIL, 2002; GODOY, 1995).

Desse modo, este estudo se delineia em três seções. A primeira aborda de forma geral a política urbana no Brasil, destacando a im-

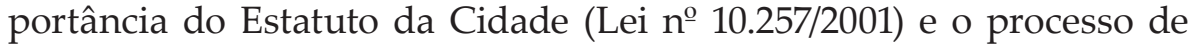
descentralização desta política na definição de instrumentos planejamento municipal, como o Plano Diretor. A segunda seção volta-se para discussões em torno das concepções de patrimônio cultural e o reflexo destas na definição de modelos de gestão dos bens culturais. Por último, tentamos estabelecer o diálogo entre as seções anteriores na análise dos Planos Diretores dos municípios de Crato e Juazeiro do Norte. Com esse intuito discute-se o contexto político e econômico em que são construídos os planos, o tipo de patrimônio cultural e gestão que é assegurada no processo de planejamento urbano.

\section{A CIDADE IDEAL: UMA ANALOGIA}

A canção "A Cidade Ideal" composta por Luis Enriquez Bacalov, Sérgio Bardotti e adaptada por Chico Buarque em 1976, para o musical dos Saltimbancos, narra a fuga de quatro animais (galinha, cachorro, jumento e gata) para a cidade, projetada em seus respectivos discursos como "ideal". Cada um tinha uma perspectiva do que se caracterizava como ideal para si mesmo e, a cidade era o espaço em que convergiam todas essas idealizações.

A convergência dessas idealizações narradas pelos personagens da canção é tecida a partir do espaço que contempla as mais diversas necessidades. $\mathrm{O}$ conceito de cidade delineado na canção e na produção teórica nos permite compreender o espaço urbano - uma vez que os animais da peça fogem do campo - o que envolvem entendimentos múltiplos. A constituição do espaço urbano perpassa a dimensão da multiplicidade. Para Lencione (2008), uma ideia comum a todas as cidades é a de aglomeração, tanto que esse conceito está presente na própria definição da palavra cidade. Pensando assim, não se pode esperar que esses aglomerados caracterizam-se pela homogeneidade.

O processo de fixação desses sujeitos em tais territórios está ainda associado à dimensão da sedentarização, que também constitui o percurso de formação do conceito de cidade (LENCIONE, 2008). Logo, a definição de cidade é atravessada por essas concepções de aglomeração e sedentarização, processos que se desenvolvem ao longo do tempo 
de formas distintas e também são organizados de maneiras diversas. Dessa forma, Lencione (2008) defende que a cidade constitui-se em um produto social que compreende a relação do homem com o meio.

Casco e Amorim (2001) são autoras que discorrem sobre esses sentidos em torno da cidade. Defendem que falar de cidades é pensar não somente em espaços, mas em tempos: justapostos, apagados, fragmentados, públicos ou privados. Para essas autoras, a trajetória de constituição das cidades permite pensá-las como o lugar do movimento, da circulação e estocagem de fluxos.

Para conformar essa mutabilidade e multiplicidade discutida por Casco e Amorim (2001) e por Lencione (2008) e pensados como espaços em permanente transformação, são estruturados sistemas normativos, que tentam contemplar as diversas demandas que emergem nessa trajetória de constituição das cidades. Diante desse processo de dinamização e transformação das configurações da cidade, são formulados instrumentos legais que preveem formas mais eficientes e igualitárias de administrar esses territórios e as relações que neles se delineiam.

A Constituição Federal de 1988 é um dos instrumentos, mais recentes, que melhor conforma tais finalidades, introduzindo a Política Urbana que prevê o papel determinante do Poder Público municipal no desenvolvimento urbano, em que deve ser guiado pelo objetivo de "ordenar o pleno desenvolvimento das funções sociais da cidade e garantir o bem-estar de seus habitantes" (BRASIL, 1988, Art.182). Nesse sentido o Plano Diretor é apontado como "o instrumento básico da política de desenvolvimento e de expansão urbana" (BRASIL, 1988, Art.182, § 1º).

A política urbana ganhou contornos específicos e aprofundados como a aprovação da Lei no 10.257 em 10 de julho de 2001, também conhecida como Estatuto da Cidade. Determina as diretrizes gerais da política urbana. Além de reafirmar o pleno desenvolvimento das funções sociais da cidade e da propriedade urbana (BRASIL, 2001, Art. $2^{\circ}$ ), a lei amplia a obrigatoriedade prevista na CF de 1988 para a elaboração do Plano Diretor para cidades com mais de vinte mil habitantes.

Com a sanção do Estatuto da Cidade, o Plano Diretor passa a ser obrigatório também para cidades integrantes de regiões metropolitanas e aglomerações urbanas; territórios onde o Poder Público municipal pretenda utilizar parcelamento ou edificação compulsórios, imposto sobre a propriedade predial e territorial urbana progressivo no tempo desapropriação (BRASIL, 1988, Art. 182, $\S 4^{\circ}$ ); de interesse turístico; de influência de empreendimentos ou atividades com significativo impacto ambiental de âmbito regional ou nacional; incluídas no cadastro nacional de Municípios com áreas suscetíveis à ocorrência de deslizamentos de grande impacto, inundações bruscas ou processos geológicos ou hidrológicos correlatos (BRASIL, 2001, Art. 41).

Entende-se pelos instrumentos normativos (BRASIL, 1988, 2001) que o Plano Diretor representa um instrumento básico, essencial e indispensável no planejamento urbano. Rolnik et al. (2014) observam que deve ocorrer a interação entre as dinâmicas de mercados econômicos 
e esse instrumento, corroborando para a redução das desigualdades sociais uma vez que ocorre a redistribuição dos riscos, assim como dos benefícios da urbanização.

Para alcançar tais finalidades o Plano Diretor se estrutura a partir de objetivos, estratégias e instrumentos que serão utilizados para atingir os objetivos, orienta os investimentos estruturais a serem feitos pelos agentes públicos e privados, traça definições dos papéis dos agentes, tem de prever critérios e formas pelos quais serão aplicados os instrumentos urbanísticos e tributários, prever também as ações estratégicas a serem implementadas (ROLNIK et al., 2014).

Dentre as perspectivas aprofundadas pelo Estatuto da Cidade está a previsão da gestão democrática participativa, que se concretizará através da inserção da participação de diferentes segmentos da sociedade civil, perpassando os processos de "formulação, execução e acompanhamento de planos, programas e projetos de desenvolvimento urbano" (BRASIL, 2001, Art. 2⿳, II). O Plano Diretor só se caracterizará em uma ferramenta útil se conseguir dialogar com a cidade real, compreendendo os problemas urbanos, percebendo ainda a efetiva capacidade de gestão do município.

Diante do exposto entende-se no presente estudo que o Patrimônio Cultural configura-se como um elemento determinante na integração da coletividade no processo de planejamento do território. Ele compreende as representações sociais, históricas e políticas implícitas na constituição destes bens culturais enquanto patrimônio.

\section{GESTÃO DO PATRIMÔNIO CULTURAL}

A definição de um bem considerado patrimônio cultural passa por uma série de processos que não se restringem a uma única dimensão das relações dos sujeitos com o território em que estão inseridos. Esse percurso é atravessado por questões que envolvem dimensões simbólicas, relacionadas à memória, história e identidade, assim como usos econômicos, políticos em que há um direcionamento para determinados fins. No entanto, um ponto de convergência nas discussões que são desenvolvidas em torno do patrimônio cultural é a compreensão de que esse se constitui como uma construção social.

Para Choay (2011, p.11) em sua origem o termo patrimônio remete às estruturas familiares, econômicas e jurídicas permitiram associar o termo patrimônio a perspectiva de "uma sociedade estável, enraizada no espaço e no tempo". No entanto, a requalificação por distintos adjetivos - genético, natural, histórico, entre outros - sofridos pelo termo ao longo do tempo o constituiu em um conceito "nômade".

Em face do trânsito entre o âmbito privado para o público, patrimônio remete ao "legado de uma geração para outra" (FONSECA, 2012, p. 14), mas guiado pela perspectiva de instrumento de unificação de determinados grupos sociais. Compreendido assim, como "legado vivo" que se recebe do passado, as referências ao conceito de patrimô- 
nio admite o mesmo como construção histórica, que conjuga o sentido de pertencimento dos indivíduos. Essa lógica de pertença assegura uma identidade cultural que representa um suporte no processo de formação do cidadão (PELEGRINI, 2007). Pensado nessa perspectiva, Canclini (2013) pontua as desigualdades e apropriação que ensejam a formação do patrimônio, defende que o processo de reflexão do mesmo pode ser desenvolvido através da sua compreensão enquanto "espaço de luta material e simbólica" (CANCLINI, 2013, p.1995).

A perspectiva delineada pelos autores supracitados nos conduz a pensar a o patrimônio cultural como uma construção social que no seu percurso de constituição perpassam pontos de tensões, que ensejam não apenas conflitos sociais, mais que conduzem ainda a (re)elaboração de instrumentos jurídicos e normativos em âmbito variados, público e privado, internacional, nacional e/ou local, implicando na estratégias de definição e intervenção sobre tais bens.

Discutir as formas e estratégias de gestão do patrimônio cultural no planejamento urbano implica pensar qual patrimônio será inserido nesse processo, uma vez que se deve considerar uma série de limitações que impossibilitam à inserção de todos os bens, materiais e imateriais, considerados pelos grupos\comunidades como elementos de representação, identidade, memória e cultura. Prevê, delimitar, legislar sobre tais dimensões a partir da perspectiva democrática, geram contradições à medida que se selecionam os bens "dignos de salvaguarda". Nesse sentido, devemos atentar para a própria ideia de patrimônio cultural entendida como uma construção social (FONSECA, 2012; CANCLINI, 2013), como espaço de lutas (CANCLINI, 2013).

Dessa forma, é possível compreender que os modelos de gestão e/ou preservação se constituem a partir de mecanismos de seleção que se pautam em critérios que se orientam por lutas políticas, sociais e econômicas. As (re)definições dos sentidos de patrimônio cultural conduziram em sua própria trajetória a necessidade de se pensar modelos de gestão condizentes com tais formulações. Podemos aqui apontar quatro modelos de gestão/intervenção sobre o patrimônio pontuada na literatura (CASTRIOTA, 2013; STARLING, 2012) e que nos auxiliará a compreender a própria previsão desse tipo de atuação nos instrumentos aqui analisados. Os principais modelos de gestão do patrimônio cultural são: tradicional ou de preservação, conservação integrada, reabilitação urbana e governança participativa e deliberativa.

O modelo de gestão tradicional ou de preservação se apoia no conceito de patrimônio entendido como bens da cultura erudita, vinculados aos segmentos sociais dominantes (CASTRIOTA, 2013; STARLING, 2012). Como uma das primeiras estratégias traçadas na estruturação de políticas no processo de gestão do patrimônio cultural orienta-se pela perspectiva imobilista, voltadas "proteção e a preservação de edificações, estruturas e outros objetos individuais" (STARLING, 2012, p. 93). Um exemplo desse modelo de gestão no Brasil pode ser encontrado no decreto $n^{\circ} 25$ de 1937, com a instituição do tombamento, em que aponta 
como o principal agente o Estado para desempenhar tais funções de preservação e proteção do patrimônio definido previamente.

A conservação integrada, entendida como um modelo formulado a partir da expansão do conceito de patrimônio cultural, com a inserção de outros bens, que não se limitam pela sua excepcionalidade, nem unicamente pela arquitetura tida como "clássica", assim como a inclusão da dimensão imaterial das representações, expressões e manifestações culturais de interesse de preservação (STARLING, 2012). Passa a contemplar, não apenas a cultura, definida como erudita, mas ainda manifestações populares e a moderna cultura de massa (CASTRIOTA, 2013; STARLING, 2012).

Esse modelo, de acordo com Zanchetti (2003), se orienta pelo princípio da necessidade de articular as ações em torno de conservar o equilíbrio da paisagem urbana e natural. Dentre os pressupostos da conservação integrada está a necessidade de abordar o planejamento e a gestão do patrimônio cultural associado à integração "nos processos mais gerais de planejamento e gestão das cidades e dos territórios, a partir de uma visão multidimensional integrada (econômica, política, cultural, ambiental e físico-espacial)" (ZANCHETTI, 2003, p. 110). Mesmo que o Estado ainda figure como o principal agente no desenvolvimento desse modelo, é inserida a perspectiva da "ação contínua como parte do processo de planejamento urbano" (STARLING, 2012, p. 96).

O modelo de reabilitação de acordo com Castriota (2013) se estabelece ao ser traçadas estratégias para o desenvolvimento da conservação a partir da realidade a qual se irá atuar. Atribuindo importância ao desenvolvimento e sustentabilidade econômica das áreas conservadas (CASTRIOTA, 2013; STARLING, 2012). Outro ponto de diferenciação apontado pelos autores para esse modelo de gestão do patrimônio cultural volta-se para os atores envolvidos, o Estado passa atuar como articulador de projetos de desenvolvimento para áreas em que atuará através da preservação, conservação e/ou revitalização, contando com a atuação de outros atores sociais (CASTRIOTA, 2013).

Por último, o modelo de gestão mais recente pontuado na literatura é o da governança participativa e deliberativa do patrimônio cultural (STARLING, 2012). Esse modelo, que encara a complexidade das concepções do patrimônio cultural e da integração destes nas políticas urbana se orienta pelo "processo progressivo de compartilhamento entre Estado e sociedade" (STARLING, 2012, p. 99). O modelo governança participativa e deliberativa pode ser entendido a partir da luta dos movimentos sociais urbanos nas décadas de 1960 e 1970, pela participação no processo de planejamento urbano, democratização da gestão, colocam em xeque a própria gestão do patrimônio cultural nesse cenário. Contexto que evidencia as reivindicações por "um novo modelo de gestão do patrimônio que privilegia os espaços de interação entre cidadãos e atores públicos e privados na formulação e implementação de políticas orientadas para o setor" (STARLING, 2012, p. 100). 
Esses modelos nos possibilitam pensar as transformações vivenciadas não apenas no campo conceitual, mas nas formas, estratégias e mecanismos de atuação do poder público nos processos de administrar o território no encalço das mudanças vivenciadas pela sociedade.

Partindo do que foi exposto, compreende-se que na sociedade atual a gestão do patrimônio cultural deve estar em consonância com as demandas da comunidade e do território em que estão inseridos esses sujeitos. A mera representação, pautadas unicamente em critérios unificadores e uniformizadores de uma ideia de nação, selecionado por determinados grupos que controlam esses processos de escolha revela-se incapaz de atender as necessidades que perpassam à gestão do patrimônio cultural, destoando da realidade socioeconômica.

Por conseguinte, a seção a seguir, se debruça sobre os instrumentos de planejamento urbano (PDDU) dos municípios de Crato e Juazeiro do Norte. Apoiado no que foi discutido até aqui, busca compreender como essas relações são estabelecidas nos municípios da Região Metropolitana do Cariri a partir do processo de planejamento urbano.

\section{Planejamento urbano e O PATRIMÔNIO CULTURAL NO CARIRI}

Os Planos Diretores dos municípios de Crato e Juazeiro do Norte se inserem na perspectiva de descentralização prevista tanto na Constituição (1988), como na política adotada pela gestão do ex-governador do estado do Ceará Tasso Jereissati. De acordo com Menezes (2011), a descentralização desenvolvida no território cearense estava em consonância com as propostas do grupo político a qual participava Tasso Jereissati, composto por jovens empresários que integravam o Centro Industrial do Ceará (CIC).

A construção dos planos ocorreu através do $O$ Projeto de Desenvolvimento Urbano e Gestão dos Recursos Hídricos (PROURB - RH) desenvolvido em parceria com o Banco Mundial, implementado no segundo mandato do ex-governador Tasso Jereissati (1995-1998), encerrado em 2005 na gestão de Lúcio Alcântara. O projeto contemplou 49 municípios cearenses considerados estratégicos no estado. Apresenta como objetivo norteador:

(...) a estruturação urbana de uma rede de cidades estratégicas, para dar suporte à interiorização do desenvolvimento, observando a preservação ambiental e a convivência com o semiárido, com vistas à melhoria da qualidade de vida da população cearense (MENEZES, 2011, p. 64-65).

Nascimento (2011, p. 247) observa que os fatores que influenciaram a Política Urbana do Governo do Estado do Ceará estruturada no PROURB podem ser encontrados no processo crescente de urbanização do Estado, a exaustão do modelo urbano brasileiro, conforme o exposto que privilegiava as grandes cidades, com atenção especial para áreas 
metropolitanas e capitais, assim como a compreensão da necessidade de interiorizar o desenvolvimento urbano, fator que permitiria a consolidação das cidades-polo e regiões estratégicas.

Logo, em sua concepção, a elaboração dos projetos dos planos diretores dos municípios do Crato e Juazeiro do Norte se inserem nessa lógica macro de possibilitar a descentralização no processo de planejamento urbano iniciada no final da década de 1990. A construção dos projetos dos planos diretores ocorreu no ano de 2000 sob responsabilidade do Consórcio VBA/Espaço Plano. As sanções dos Planos Diretores, no entanto, ocorreram em períodos distintos. Crato sancionou em 2005 (Lei no 2.279) e Juazeiro do Norte (Lei no 2.572) no ano 2000.

Os municípios estudados integram a Região Metropolitana do Cariri que estabelecem entre si distintas relações, econômicas, sociais, ambientais e culturais. Estas relações, em sua dimensão socioeconômica, podem ser visualizadas no processo de conurbação entre os municípios do CRAJUBAR ${ }^{2}$, como na legitimação dessas relações físico-espaciais com aprovação da Lei Complementar Estadual do Ceará no 78 que instituiu em 29 de junho de 2009 a Região Metropolitana do Cariri, incluído ainda municípios limítrofes localizados no cariri Cearense - Caririaçu, Jardim, Missão Velha, Nova Olinda, Santana do Cariri, Farias Brito. Diante do que foi exposto até o presente momento, podemos traçar algumas considerações em torno do Patrimônio Cultural, tanto na sua materialidade como imaterialidade, delineadas na estruturação dos Planos Diretores dos municípios aqui estudados.

Como já foi ressaltado, por se integrarem a um projeto do governo estadual, PROURB-CE, os Planos Diretores de Crato e Juazeiro do Norte ainda permanecem os mesmos elaborados pelo consórcio VBA/ Espaço Plano, apresentado semelhanças ao longo de toda sua redação. Nesse primeiro olhar para a apresentação do Patrimônio Cultural delineado nos Planos Diretores um dos aspectos que podemos ressaltar volta-se para a dimensão preservacionista, focados na dimensão material.

2 CRAJUBAR refere-se ao processo de conurbação dos municípios 
QUADRo 1 - Dimensão preservacionista dos Planos Diretores de Crato e Juazeiro do Norte.

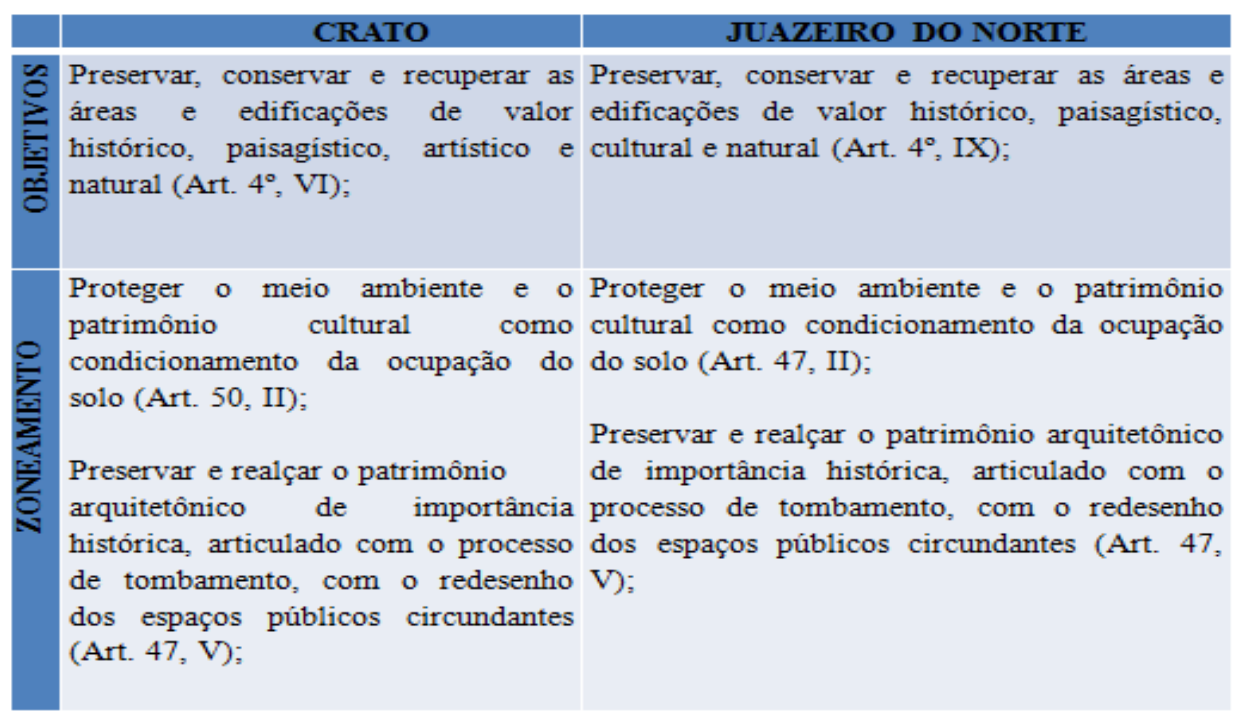

Fonte: (CEARÁ/CRATO, 2005; CEARÁ/ JUAZEIRO DO NORTE, 2000).

A preservação dos bens culturais é entendida como uma das expressões mais significativas ao longo de todos os documentos analisados no que se refere ao patrimônio cultural. No entanto, a dimensão do preservar circunscreve-se a um tipo de bem específico, o material.

A materialidade do patrimônio cultural observado os Planos Diretores de Crato e Juazeiro do Norte, pode ser visualizada, não apenas nos artigos que versam sobre os objetivos desses instrumentos do planejamento urbano, como ainda nas determinações em torno da definição das zonas de ocupação e uso do solo. Mas ainda no espaço que ganha o instrumento de proteção, o tombamento, nos planos de Crato e Juazeiro do Norte.

Seguindo a própria ordem de estruturação desses instrumentos, é previsto de início, com a finalidade de promover, através da atuação do poder público, o "pleno desenvolvimento das funções sociais da cidade e garantir bem-estar de seus habitantes" (CEARÁ/CRATO, 2005; CEARÁ/ JUAZEIRO DO NORTE, 2000), os objetivos fundamentais da Política Urbana - artigo $4^{\circ}$ dos dois documentos. Dentre os objetivos fundamentais, previstos de forma idêntica nos dois planos, está o a orientação de "preservar, conservar e recuperar as áreas e edificações de valor histórico, paisagístico, cultural e natural".

Os objetivos fundamentais tecidos no espaço dedicado a Política Urbana introduzem a concepção que orienta toda a inserção do patrimônio cultural no processo de planejamento urbano construída nos planos diretores, seguindo, como visto anteriormente o modelo de gestão identificado como tradicional/preservacionista (CASTRIOTA, 2013; STARLING, 2012).

A inserção do patrimônio cultural nos planos diretores dos respectivos municípios segue as concepções que caracterizam o mo- 
delo de gestão do patrimônio preservacionista (CASTRIOTA, 2013; STARLING, 2012). Apresentado como principal mecanismo de atuação a preservação de bens materiais que se apresentam como representativos. No entanto, o caráter de representatividade está circunscrito a valores limitantes dos espaços urbanos como "aspecto relevante do desenho urbano" e/ou "patrimônio arquitetônico da zona central".

O caráter preservacionista fica latente na subseção do Tombamento. O tombamento é apresentado como instrumento de operacionalização do PDDU - Título II, Capítulo II, artigo $15^{\mathrm{o}} \mathrm{em}$ ambos os planos. Insere-se, juntamente com o Estudo Prévio de Impacto Ambiental, Programa de Formação de Estoque de Terras e a Desapropriação, como Instrumentos Urbanísticos/Ambientais. Como definição deste instrumento é apresentada, de forma idêntica nos dois planos, que se constituem em:

(...) limitação administrativa e de disponibilidade a que estão sujeitos os bens integrantes do patrimônio ambiental, histórico, paisagístico e cultural do município, cuja conservação e proteção sejam de interesse público (CEARÁ/ CRATO, 2005; CEARÁ/JUAZEIRO DO NORTE, 2000).

O conceito de tombamento reforça além da dimensão preservacionista, a materialidade dos bens acautelados, uma vez que se dedica ao patrimônio material. A representatividade do patrimônio cultural é apresentada nestes documentos através das "edificações, obras e monumentos naturais de interesse de preservação, aquelas que se constituírem em elementos representativos do patrimônio ambiental urbano do município pelo seu valor histórico, cultural, social, funcional, técnico ou afetivo" (CEARÁ/CRATO, 2005, Art. 39; CEARÁ/JUAZEIRO DO NORTE, 2000, Art. 34). A identificação destes bens constitui-se a partir da consideração dos seguintes critérios:

QUAdro 2 - Critérios de Identificação do Patrimônio Cultural nos Planos Diretores.

\begin{tabular}{|c|c|}
\hline \multicolumn{2}{|c|}{ CRÍTERIOS DE IDENTIFICAÇÃO DAS EDIFICAÇÕES } \\
\hline Historicidade & $\begin{array}{l}\text { Relação da edificação com a história social } \\
\text { local }\end{array}$ \\
\hline Caracterização arquitetônica & $\begin{array}{l}\text { Estilo arquitetônico de determinado período } \\
\text { histórico }\end{array}$ \\
\hline $\begin{array}{l}\text { Situação em que se encontra a } \\
\text { edificação }\end{array}$ & Necessidade ou não de reparos \\
\hline Representatividade & $\begin{array}{l}\text { Exemplares significativos dos diversos estilos } \\
\text { arquitetônicos e períodos de urbanização }\end{array}$ \\
\hline Raridade arquitetônica & $\begin{array}{l}\text { Apresentação de formas valorizadas, porém } \\
\text { com ocorrência pouco comum; }\end{array}$ \\
\hline Valor cultural & $\begin{array}{l}\text { Qualidade que confere à edificação } \\
\text { permanência na memória coletiva }\end{array}$ \\
\hline Valor ecológico & $\begin{array}{l}\text { Relação existente entre os diversos elementos } \\
\text { naturais bióticos e abióticos e sua significância }\end{array}$ \\
\hline Valor paisagístico & $\begin{array}{l}\text { Qualidade visual de elemento natural de } \\
\text { características ímpares }\end{array}$ \\
\hline Nível de interesse do bem tombado & Municipal, estadual ou federal \\
\hline
\end{tabular}

FONTE: (CEARÁ/CRATO, 2005; CEARÁ/ JUAZEIRO DO NORTE, 2000). 
Nesse processo de identificação, apresentado da mesma forma nos dois planos, o gestor deve considerar os seguintes critérios que se associam as dimensões arquitetônicas e materiais do patrimônio cultural. Excluindo do processo de planejamento urbano as dimensões imateriais do patrimônio cultural, uma vez que, sequer são previstas qualquer forma de salvaguarda.

As dimensões limitantes não são percebidas apenas na materialidade do patrimônio que orienta esse modelo de gestão. Há ainda limitações que podem ser sentidas nas estratégias adotadas por ambos os municípios no que concerne ao desenvolvimento do território. Dentre os objetivos estratégicos expostos pelos planos está previsto a promoção de condições que garantam, de forma estratégica, a sustentabilidade do desenvolvimento. Para tal, apresenta como Plano Estratégico, nos dois municípios, quatro linhas de atuação:

QUADro 3 - Plano Estratégico de Juazeiro do Norte

\section{PLANO ESTRÁTÉGICO JUAZEIRO DO NORTE}

\begin{tabular}{|l|l|}
\hline Linha Estratégica 1 & $\begin{array}{l}\text { Juazeiro do Norte deverá ser um importante centro de turismo } \\
\text { religioso da América Latina. }\end{array}$ \\
\hline Linha Estratégica 2 & $\begin{array}{l}\text { Juazeiro do Norte deverá ser um Centro Comercial regional de } \\
\text { qualidade. }\end{array}$ \\
\hline Linha Estratégica 3 & $\begin{array}{l}\text { Juazeiro do Norte deverá ter uma economia industrial forte e } \\
\text { descentralizada, com produtos de valor agregado cada vez } \\
\text { mais. }\end{array}$ \\
\hline Linha Estratégica 4 & $\begin{array}{l}\text { Juazeiro do Norte deverá ser um município atraente e } \\
\text { equilibrado fisica e socialmente. }\end{array}$ \\
\hline
\end{tabular}

FONTE: (CEARÁ/JUAZEIRO DO NORTE, 2000)

QUADro 4 - Plano Estratégico de Crato.

\section{PLANO ESTRÁTÉGICO CRATO}

Linha Estratégica 1 Crato deverá ser um importante centro de turismo do sul do Ceará.

Linha Estratégica 2 Crato deverá ser uma cidade de ensino especializado de qualidade.

Linha Estratégica 3 Crato deverá ter uma economia industrial forte e descentralizada, com produtos de valor agregado cada vez mais.

Linha Estratégica 4 Crato deverá ter uma economia agrícola de produtos diferenciados para o mercado nordestino.

FONTE: (CEARÁ/CRATO, 2005).

Podemos observar que o desenvolvimento do território não se vincula em nenhuma das linhas estratégicas ao patrimônio cultural, ou não há uma relação visível. Nesse sentido abre margem para as interpretações, pois uma forma de enxergar tal relação poderia ser vista na linha estratégia 1 delineada em cada plano, no entanto fica restrita a dimensão do turismo. Porém, os elementos básicos para execução de 
tais estratégias também não contemplam o patrimônio cultural como um instrumento para execução destas.

Art. $8^{\mathrm{o}}$ - Ficam definidos como componentes básicos para consecução dos objetivos traçados na Linha Estratégica 1:

I - criar infraestrutura básica e social para promover e incrementar o turismo religioso, com vistas à manutenção e preservação dos valores culturais desenvolvidos pela população local e assimilados pelos visitantes;

II - aproveitar sinergias do turismo religioso em concomitância comoutrasformas deturismoverificadasem Juazeiro do Norte e municípios circunvizinhos (CEARÁ/ JUAZEIRO DO NORTE, 2000).

Art. $7^{\mathrm{O}}$ - Ficam definidos como componentes básicos para a consecução da Linha Estratégica 1:

I - criar infraestrutura para promover o turismo ecológico;

II - aproveitar sinergias do turismo religioso com o Município de Juazeiro do Norte (CEARÁ/CRATO, 2005).

Nesse sentido, é possível afirmar que as relações entre o patrimônio cultural e outras demandas da sociedade, como o próprio desenvolvimento do território não são representados nos respectivos planos diretores. Há uma inserção pontual e restrita no que diz ao patrimônio, preservar bens materiais. Seleção que a partir de determinados critérios, estruturados e apresentados como significantes, circunscreve o patrimônio cultural a bens imóveis, a arquitetura e ao passado. No percurso de estudo podemos identificar e pontuar alguns desafios a serem enfrentados no processo de inserção do patrimônio cultural no planejamento urbano. O mais latente centra-se na própria concepção de patrimônio cultural que é tecida nos planos diretores dos municípios em estudo e que perpassam todas as relações e que são estabelecidas entre esse e o planejamento urbano. Tal ideia de patrimônio cultural vai ao encontro dos constructos desenvolvidos ainda na década de 1930. Alinhada às dimensões imobilistas das formas de atuar sobre o patrimônio cultural.

Essa dimensão pode ser entendida pela própria desatualização dos Planos Diretores dos municípios de Crato e Juazeiro do Norte. Tanto a Constituição Federal de 1988, como o Estatuto da Cidade prevê a atualização dos planos a cada dez anos. Os instrumentos do planejamento apresentados em seus portais oficiais ainda são os desenvolvidos pelo Consórcio VBA/Espaço Plano em 2000. Logo, a própria ideia de patrimônio cultural não contempla a diversidade do conceito e as suas dimensões, como foi possível observar no processo histórico de constituição do conceito no campo normativo.

A desatualização dos planos implica o não acompanhamento das próprias mudanças sofridas pela sociedade. Um exemplo latente desse fato pode ser entendido no instrumento normativo que institui o 
Registro de Bens Culturais de Natureza Imaterial que constituem patrimônio cultural brasileiro regulamentado pelo Decreto no 3.551/2000 sancionado no mês de outubro, após a elaboração dos projetos dos planos. Ou seja, os planos diretores dos municípios de Crato e Juazeiro do Norte não apresentam outros instrumentos de preservação/proteção do patrimônio cultural, pois não acompanham no mesmo passo as transformações vivenciadas no próprio campo normativo.

Essa desatualização dos planos, principalmente no campo de gestão do patrimônio cultural pode ser constatada na dificuldade dos instrumentos normativos brasileiro em acompanhar a ampliação do próprio conceito de patrimônio cultural, impossibilitado por uma compreensão eficaz acerca das formas de proteção e gestão do patrimônio (FONSECA, 2003; SANTOS, 2001).

Por fim, há ainda um desencontro entre o que está previsto na lei e o que é executado. Aqui apresentamos como caso simbólico dos conflitos vivenciados em Juazeiro do Norte. Apesar de não considerarmos o tombamento ou o registro como únicos meios de preservar e valorizar, uma vez que nesses instrumentos consequentemente pressupõe maior participação do poder público/Estado, considera-se tais estratégias no próprio contexto nacional, como um dos principais meios de intervenção se associamos ao modelo de gestão preservacionista previsto no PDDU do município.

O município de Juazeiro do Norte, a título de exemplo, é o único do eixo CRAJUBAR (Crato, Juazeiro do Norte e Barbalha), que não possui bens tombados ou registrados a nível estadual ou nacional. No entanto, foi aprovado o decreto $\mathrm{n}^{\circ}$ 459, de 27 de maio de 2019 que institui o tombamento provisório de vinte e quatro bens culturais no município, com as seguintes considerações:

(...) o dever de proteger os documentos, as obras e outros bens de valor histórico e cultural, os monumentos, as paisagens naturais notáveis e os Sítios Arqueológicos locais;

(...) a necessidade de promover a proteção do patrimônio histórico-cultural local;

(...) a imprescindibilidade de impedir a destruição e a descaracterização de bens de valor histórico, artístico ou cultural;

(...) o significado e o possível valor histórico, arquitetônico e cultural das edificações abaixo registradas e a importância de preservar marcos referenciais arquitetônicos que testemunharam as fases da evolução temporal desta cidade;

(...) a possibilidade do Poder Público Municipal realizar procedimento administrativo objetivando sujeitar a restrições parciais os bens imóveis cuja conservação seja de interesse público, por sua vinculação a fatos memoráveis da história ou por seu valor arqueológico, etnológico, bibliográfico ou artístico; 
Entre o dever e a necessidade, há um caráter imediatista, uma vez que o episódio da demolição do Casarão de Juvêncio Santana causou insatisfação - na falta de adjetivo melhor - e sanções legais, como a multa aplicada ao proprietário que demoliu o prédio sem autorização. Demolição irregular, pois a "edificação era de interesse histórico cultural de Juazeiro do Norte" (DIÁRIO DO NORDESTE, 2020).

Essa situação gera ambiguidades, pois na falta de instrumentos legais, como decreto $\mathrm{n}$ 459 e a própria fragmentação das ações que incluem o imóvel ao grupo de "interesse" do município, a formas de lidar como esses bens ficam sujeita a própria autonomia do proprietário.

No caso do Casarão de Juvêncio Santana, as medidas podem ser percebidas nas implicações legal do ato com a multa ao proprietário, a sua "reconstrução" (DIÁRIO DO NORDESTE, 2020a) - que na verdade será uma replicação, uma vez que o prédio foi totalmente destruído - e na sanção de um decreto que de uma única vez que apresenta dezenas de bens imóveis considerados de interesse do município (CEARÁ, 2019). Logo, tomando esses episódios recentes, e simbólicos, podemos perceber as distâncias entre o que foi posto a quase duas décadas atrás e a própria ações em prol da preservação. Caso que evidencia a fragmentação e desarticulação nos processos de se pensar o patrimônio cultural inserido no planejamento urbano.

Diante do exposto, há desafios a serem superados na inserção da diversidade do patrimônio cultural no planejamento urbano. Questão que fica latente com a exclusão das manifestações, práticas, modos de fazer, viver e criar que integram a identidade dos munícipes das regiões estudadas, assim como do território, processo de seleção que exclui e segrega dentro desse processo de pensar o espaço urbano a diversidade de bens culturais que (co)existem no território.

\section{CONCLUSÕES}

As discussões em torno da temática possibilitam perceber o quanto é fluído a construção e constituição desse conceito na teoria, nos instrumentos normativos. Nessa perspectiva, a discussão esboçada acerca desse percurso possibilitaram visualizar a mutabilidade e "nomadismos" que atravessou os debates em torno do conceito de patrimônio cultural, transições e (re)significações ao qual perpassam o conceito.

Nomadismo que podemos visualizar nos tratados e convenções internacionais, que se apoiam no decorrer do tempo em perspectivas distintas nas formas e estratégias de lidar com as questões que envolvem o patrimônio. Diante do exposto, pensar o patrimônio cultural a partir do planejamento urbano encaminhou-se pela própria necessidade de pensar por essa lógica pautada nas transformações. Evidenciando as limitações que se encontram na própria desatualização dos planos diretores dos municípios em análise.

As noções traçadas em torno do conceito de patrimônio trazem 
em seu bojo a própria noção de coletividade, nem que seja forjada, se pensarmos pela perspectiva de Canclini (2013) ao observarem que nem todos se inserem nesse processo de seleção. No entanto, esta ideia de coletividade nos permite pensar o próprio espaço da cidade, uma vez que este é, e deve ser, um lugar para todos. Logo, trabalhamos com conceitos que convergem e que em teoria, e nos instrumentos normativos, deveriam coexistir de forma equilibrada.

No entanto, a partir da análise aqui esboçada podemos considerar que tal equilíbrio ainda não existe, até o nomadismo do conceito não foi identificado, a medida que os sentidos de Patrimônio Cultural estão alicerçados nos sentidos construídos na década de 1930. Há desafios e desencontros a serem superados, sendo a cidade ideal uma ideia utópica na conjuntura atual. Tomado os planos diretores como instrumentos básicos para se pensar e planejar o território podemos constatar que a inserção do patrimônio cultural como elemento essencial para permitir o "pleno desenvolvimento" ainda não se configura como uma perspectiva real. Mas, quase uma "obrigação" a ser pontuada, em que não se teve o trabalho de alterar a própria redação dos planos para enfatizar a diversidade dos bens culturais de cada território.

As estratégias adotadas nos planos diretores de inter-relação entre patrimônio cultural e o planejamento urbano mostram-se defasadas e incapazes de contemplar o conceito de patrimônio cultural e a sua diversidade. Logo, assim estruturado, há ainda de se pensar estratégias não apenas de tornar efetiva a integração entre patrimônio cultural e o planejamento urbano, de forma contínua e efetiva. Estabelecendo como mecanismo de atuação nesse processo de planejamento urbano ações integradas com outros campos, como educação e economia.

Nesse sentido, tentar articular o patrimônio cultural - seja ele consagrado pela norma (tombado ou registrado) ou reconhecido pela sociedade, com as demandas das comunidades em que estão inseridos, uma vez que entende-se que a sociedade civil colocada a parte no processo de valorização, preservação e promoção do patrimônio configura-se em um empecilho na própria integração deste no processo de planejamento urbano.

Podemos considerar a fragmentação da atuação em relação ao que se entendem como campos diversos se concretizam na dificuldade de entender o patrimônio cultural como um elemento que compõem a vivência, cotidiano dos sujeitos que transitam nesses espaços. Sobressai-se o conjunto - não são fatores isolados - de desencontros que podemos perceber nesse pequeno espaço de análise. $\mathrm{O}$ mais gritante é a cópia dos instrumentos de planejamento, são idênticos - salvo uns poucos artigos e incisos- os planos diretores de Crato e Juazeiro do Norte. A desatualização dos mesmos, um sancionado em 2000 (Juazeiro do Norte) e o outro em 2005 (Crato). Diante disso, torna-se mais fácil identificar as dificuldades, falhas, desajustes.

Logo, o patrimônio cultural na perspectiva de planejamento urbano analisado através dos planos diretores de Crato e Juazeiro do 
Norte figura em aspectos limitados, centrados na materialidade dos bens. Se partirmos para o que já foi selecionado como patrimônio cultural (tombado ou registrado) fica latente a própria fragmentação na atuação, uma vez que esses ainda são encarados como algo a parte e não integrado às dinâmicas da sociedade.

Diante disso, podemos identificar desafios, a partir dos casos analisados, a serem superados na inserção do patrimônio cultural no processo de planejamento urbano. Podemos afirmar que há a necessidade se enfrentar uma série de desafios estruturais e institucionais no próprio processo de efetivação da gestão democrática, participativa em prol da construção de um território construído de forma equilibrada social e culturalmente, deslocando a atuação centrada no poder do Estado/poder público de determinar e controlar os processos que atravessam a configuração do que é colocado como patrimônio cultural no planejamento urbano, assim como os seus usos nessa trajetória. Consideramos ainda que atuação fragmentada quer seja do poder público, da universidade, ou da sociedade civil, não será capaz de superar as lacunas existentes e persistentes nos instrumentos de planejamento urbano. Distanciando-se assim a efetividade de uma "Cidade Ideal", que abrace diversidades, pleno desenvolvimento das funções sociais da cidade e garantir o bem-estar de seus habitantes (BRASIL, 1988) e o exercício da cidadania. Inserir a diversidade, a pluralidade, identidades, memória, saberes, valores, reconhecimento e pertencimento mais do que simbólico revela-se como um elemento determinante na trajetória de constituição dessa "Cidade ideal", um lugar que acolhe a todos.

Consideramos que o objetivo proposto foi alcançado a medida que discutimos e analisamos a inserção do patrimônio cultural no planejamento urbano no municípios de Crato e Juazeiro do Norte. Entretanto, destacamos que essa é uma análise que não se esgota, uma vez que os próprios instrumentos analisados devem ser revisados a cada dez anos. Desse modo, que observamos que a desatualização permite inferir sobre os desafios a serem enfrentados na constituição de territórios alicerçados na perspectiva da diversidade, do exercício da cidadania e nas representações através do Patrimônio Cultural, articulando assim a cidade ideal com a cidade real. 


\section{REFERÊNCIAS BIBLIOGRÁFICAS}

ALBUQUERQUE, Umbelino Peregrino de. Patrimônio Cultural: uma construção da cidadania. Educação Patrimonial reflexões e práticas. João Pessoa: Superintendência do IPHAN na Paraíba, 2012.

BRASIL. República Federativa do Brasil. Constituição da República Federativa do Brasil: texto promulgado em de 5 de outubro de 1988. Disponível em: <http:// www.planalto.gov.br/ccivil_03/constituicao/ constituicaocompilado.htm>..Acesso em fev. de 2020.

BRASIL. Decreto-lei no ${ }^{2}$, de 30 de novembro de 1937. Organiza a proteção do patrimônio histórico e artístico nacional. Rio de Janeiro, RJ: Presidência da República, 1937. Disponível em: <http://www.planalto.gov.br/ccivil_03/DecretoLei/Deloo25.htm\#art19\%C2\%A72>. Acesso em fev. de 2020.

BRASIL. Decreto $\mathbf{n}^{\mathbf{0}}$ 3.551, de 2 de outubro de 2000. Institui o registro de bens culturais de natureza imaterial que constituem patrimônio cultural brasileiro, cria o Programa Nacional do Patrimônio Imaterial e dá outras providências. Disponível em: <http://www.iphan.gov.br >. Acesso em jan. de 2020

BRASIL. LEI No 10.257, DE 1o DE JULHO DE 2001. Estatuto da Cidade. Brasília, 2001. Disponível em: < http://www.planalto.gov. br/Ccivil_03/leis/LEIS_2001/L10257.htm>. Acesso em jan. de 2020.

CANCLINI, Nestor Garcia. A socialização da arte: Teoria e prática na América Latina. São Paulo, Editora Cultrix, 1980. O patrimônio cultural e a construção imaginária do nacional. Cidade: Revista do Patrimônio Histórico e Artístico Nacional, n. 23. Instituto do Patrimônio Histórico e Artístico Nacional, MEC, 1994.

Nestor Garcia. Culturas Híbridas: estratégias para entrar e sair da modernidade. $4^{\text {a }}$ edição. São Paulo: Editora: EDUSP, 2013.

CASCO, Ana Carmem Amorim Jará; AMORIM, Ana Carmen. Reinventando a cidade: um diálogo entre Marco Polo e o Imperador. Revista do Patrimônio Histórico e Artístico Nacional, 2001, 29: 83-101.

CASTRIOTA, Leonardo Barci. Intervenções sobre o patrimônio urbano: modelos e perspectivas. Fórum Patrimônio: ambiente construído e patrimônio sustentável, 2013, 1.1.

CAVALCANTI, L. O cidadão moderno. In: Cidadania: Revista 
do Patrimônio Histórico e Artístico Nacional, n. 24. Instituto do Patrimônio Histórico e Artístico Nacional, MEC, 1996, p. 112.

CEARÁ. Lei no 2.279, de 20 de abril de 2005. Dispõe sobre o Plano Diretor de Desenvolvimento Urbano, PDDU de Crato e dá outras providências. Prefeitura municipal, Crato, CE, 2000. Disponível em: <http://conteudo.ceara. gov.br/content/aplicacao/SDLR-PDDU/_includes/PDFs/ crato_1-LeidoPlanoDiretor.pdf $>$. Acesso em: jan. de 2020.

CEARÁ. Decreto-lei $\mathbf{n}^{\circ} \mathbf{2 . 5 7 2}$, de o8 de setembro de 2000. Dispõe sobre o Plano Diretor de Desenvolvimento Urbano, PDDU de Juazeiro do Norte e dá outras providências. Prefeitura municipal, Juazeiro do Norte, CE, o8 de setembro de 2000. Disponível em: <http://www2.juazeiro.ce.gov.br/ Legislacao/LEI\%202572-2000. pdf >. Acesso em: jan. de 2020.

CEARÁ. DECRETO N 459, DE 27 DE MAIO DE 2019. Institui o Tombamento Provisório de diversos bens localizados no Município de Juazeiro do Norte/CE. Disponível em: $<$ https://www.juazeiro.ce.gov.br/Imprensa/DiarioOficial/Num4993-28052019/>. Acesso em: jan. de 2020.

CHOAY, Françoise. A alegoria do patrimônio. Unesp, 2011. COSTA, Everaldo Batista da. Patrimônio e território urbano em cartas patrimoniais do século XX. FinisterraRevista Portuguesa de Geografia, n. 93, p. 5-28, 2012.

DIÁRIO DO NORDESTE. Após demolição de casarão, em Juazeiro do Norte, proprietário será multado em quase R\$ 120 mil. Disponível em <http://blogs.diariodonordeste. com.br/cariri/cidades/juazeiro-do-norte/apos-demolicao-decasarao-em-juazeiro-do-norte-proprietario-sera-multadoem-quase-r-120-mil/21785>. Acesso em: jan. de 2020.

DIÁRIO DO NORDESTE. Reconstrução da fachada do casarão de Juvêncio Santana não segue a arquitetura original. Disponível em $<\mathrm{http}$ ://blogs. diariodonordeste.com.br/cariri/cidades/juazeiro-donorte/apos-demolicao- Acesso em: jan. de 2020.

FONSECA, Maria Cecília Londres. O patrimônio cultural na formação das novas gerações: algumas considerações. Educação patrimonial: reflexões e práticas. João Pessoa: Superintendência do Iphan na Paraíba, 2012, 14-21. - Maria Cecília Londres. Para além da pedra e cal: por uma concepção ampla de patrimônio cultural.In: Memória e Patrimônio: Ensaios 
Contemporâneos. Rio de Janeiro: DP\&A, 2003.

FUNARI, Pedro Paulo; PELEGRINI, Sandra.

Patrimônio histórico e cultural. Zahar, 2006.

GIL, Antônio Carlos. Como classificar as pesquisas. In:

Como elaborar projetos de pesquisa, v. 4, p. 44-45, 2002.

GODOY, Arilda Schmidt. Pesquisa qualitativa:

tipos fundamentais. Revista de Administração

de empresas, v. 35, n. 3, p. 20-29, 1995.

JUAZEIRO DO NORTE. Decreto ${ }^{\circ}$ 459, de 27 de Maio

De 2019. Institui o Tombamento Provisório de diversos bens localizados no Município de Juazeiro do Norte/CE. Prefeitura municipal, Juazeiro do Norte, CE, o8 de setembro de 2000. Disponível em: <https://juazeiro.ce.gov.br/www2/ Legislacao/decretos/2019/DECRETO\%20N\%20459-\%20 Institui $\% 200 \% 20$ Tombamento $\% 20$ Provisorio $\% 20 d e \% 20$ diversos $\%$ 2obens $\%$ 2olocalizados $\% 20$ no $\%$ 2oMunicipio $\% 20 d e \% 20$ Juazeiro\%20do\%20NorteCE.pdf>. Acesso em: jan. de 2020.

LENCIONE, Sandra. Observações sobre o conceito de cidade e urbano. GEOUSP: Espaço e Tempo, n. 24, p. 109-123, 2008.

MINAYO, Maria Cecília DE Souza; DESLANDES, Suely Ferreira; GOMES, Romeu. Pesquisa social: teoria, método e criatividade. Editora Vozes Limitada, 2011.

NASCIMENTO, José Clewton do. (Re) descobriram o Ceará? Representações dos sítios históricos de Icó e Sobral: entre areal e patrimônio nacional. SciELO-EDUFBA, 2011.

PELEGRINI, Sandra de Cássia Araújo. A gestão do patrimônio imaterial brasileiro na contemporaneidade. História (São Paulo), 2008, 27.2: 145-173.

Sandra de Cássia Araújo. O patrimônio

cultural e a materialização das memórias individuais e coletivas. Patrimônio e Memória, 2007a, 3.1: 87-100.

PELEGRINI, Sandra de Cássia Araújo. O patrimônio cultural no discurso e na lei: trajetórias do debate sobre a preservação no Brasil. Patrimônio e Memória, 2007b, 2.2: 54-77. Sandra; FUNARI, Pedro Paulo. O que é patrimônio cultural imaterial. Brasiliense, 2017.

ROLNIK, Raquel et al. Plano Diretor Participativo: guia para elaboração pelos municípios e cidadãos. 2004.

SANTOS, Carlos Nelson Ferreira dos. Preservar não é tombar, 
renovar não é pôr tudo abaixo. Revista Projeto, 1986, 86: 59-63. , Cecilia Rodrigues dos. Novas fronteiras

e novos pactos para o patrimônio cultural. São Paulo em perspectiva, 15.2: 43-48, 2001.

SANTOS JUNIOR, Orlando Alves dos; MONTANDON, Daniel Todtmann. Os Planos Diretores Municipais pósEstatuto da Cidade: balanço crítico e perspectivas. 2011.

STARLING, Mônica Barros de Lima . Entre a lógica de mercado e a cidadania: os modelos de gestão do patrimônio cultural. Políticas Culturais em Revista, 2012, 5.1: 91-108.

UNESCO. Convenção para a Protecção do Património Mundial, Cultural e Natural. 1972. Disponível em: < https://whc. unesco.org/archive/convention-pt.pdf $>$. Acesso em fev. de 2020.

UNESCO. Gestão do Patrimônio Mundial cultural - Manual de referência do patrimônio mundial. Brasília : UNESCO Brasil, 2016.

VECCHIATTI, Karin. Três fases rumo ao desenvolvimento sustentável: do reducionismo à valorização da cultura.

São Paulo em Perspectiva, 2004, 18.3: 90-95.

ZANCHETTI, Silvio Mendes. Conservação integrada e planejamento urbano: uma revisão. Cadernos de Estudos Sociais, 2003, 19.1. 